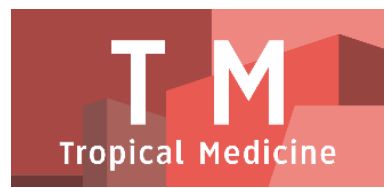

PAPER - OPEN ACCESS

\title{
Keselamatan Dan Kesehatan Kerja (K3) Pada Nelayan Di Pos Upaya Kesehatan Kerja (Pos Ukk) Puskesmas Belawan
}

Author : : Isyatun Mardhiyah Syahri

DOI $\quad: 10.32734 /$ tm.v1i1.69

Paper Page : $202-206$

Volume 1 Issue 1 - 2018 TALENTA Conference Series: Tropical Medicine (TM)

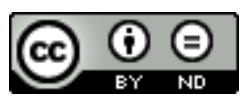

This work is licensed under a Creative Commons Attribution-NoDerivatives 4.0 International License.

Published under licence by TALENTA Publisher, Universitas Sumatera Utara
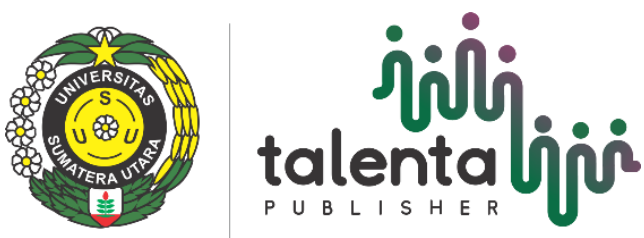


\title{
i talenta i̊jị TALENTA Conference Serles \\ Available online at https://talentaconfseries.usu.ac.id
}

\section{Keselamatan Dan Kesehatan Kerja (K3) Pada Nelayan Di Pos Upaya Kesehatan Kerja (Pos Ukk) Puskesmas Belawan}

\author{
Isyatun Mardhiyah Syahria,*, Maya Fitria ${ }^{a}$ \\ ${ }^{a}$ Fakultas Kesehatan Masyarakat, Universitas Sumatera Utara, Medan 20155, Indonesia \\ iisyahri@ymail.com
}

\begin{abstract}
Abstrak
Keselamatan dan kesehatan kerja (K3) pada nelayan saat melakukan pekerjaan sangat perlu mendapat perhatian, kecelakaan kerja bisa saja terjadi ketika berada dilaut dengan kondisi cuaca yang bisa saja berubah, begitu juga dengan gangguan kesehatan yang diakibatkan oleh pekerjaan. Selain itu kondisi perahu harus diperhatikan dan alat pelindung diri harus tersedia karena merupakan faktor penting dalam menjaga keselamatan. Penelitian dilakukan dengan tujuan untuk mengetahui kejadian kecelakaan kerja dan keluhan yang dirasakan saat bekerja. Jenis penelitian ini adalah deskriptif, lokasi penelitian dilakukan di Pos Upaya Kesehatan Kerja (Pos UKK) nelayan wilayah kerja Puskesmas Belawan. Hasil penelitian menunjukkan bahwa jenis kecelakaan yang terjadi adalah terpeleset, kapal karam, tenggelam, kena bisa binatang laut, terpatuk ular, terkena engkol mesin dan terkena jaring. Selain mengalami kecelakaan kerja, nelayan juga merasakan keluhan saat bekerja antara lain nyeri punggung, gatal-gatal, batuk, pusing, gangguan pendengaran, kebas pada tangan, muntah-muntah, dan sakit pinggang. Kecelakaan kerja yang sering terjadi pada nelayan adalah terkena bisa binatang laut, sedangkan keluhan yang paling banyak dirasakan adalah nyeri punggung. Disarankan agar nelayan lebih berhati-hati pada saat bekerja, perbaikan sikap kerja agar lebih ergonomi dan menggunakan pakaian pelindung dengan lengan panjang, serta menggunakan pelampung.
\end{abstract}

Kata Kunci: Keselamatan dan Kesehatan Kerja (K3); Kecelakaan Kerja; Keluhan Saat Bekerja; Nelayan

\section{Pendahuluan}

Kecelakaan kerja bisa terjadi dimana saja, termasuk ketika nelayan sedang melakukan pekerjaannya, begitu juga dengan keluhan yang dirasakan pada saat bekerja sehingga keselamatan dan kesehatan kerja (K3) pada nelayan perlu diperhatikan. Keselamatan dan kesehatan kerja merupakan hak bagi setiap pekerja baik pekerja yang bekerja disektor informal maupun formal sebagaimana telah diatur dalam UU 13 Tahun 2003 tentang ketenagakerjaan.

Kajian terhadap nelayan penyelam tradisional di pulau bungin, NTB menunjukkan bahwa 57,5\% menderita nyeri persendian dan gangguan pendengaran 11,3\% serta menderita kelainan pernafasan berupa sesak nafas [3]. Penelitian yang dilakukan Dharmawirawan dan Robiana Modjo [4], yang menyatakan bahwa bahaya yang dihadapi nelayan antara lain adalah ombak, lantai licin, duri ikan, terjepit, bahan bakar mesin kompresor, selang api korosif, tekanan udara pada tabung mesin kompresor, tuas terlepas, karang, gigitan biota laut, selang tertekuk, terputus, atau bocor dan tubuh yang tersangkut baling-baling kapal. Bahaya kesehatan meliputi ergonomi, kebisingan, tekanan ekstrim, temperatur dingin, temperatur panas, sengatan ikan dan karang beracun, gas $\mathrm{CO}, \mathrm{CO} 2$ dan nitrogen. N. Bull et.al [5] menyatakan bahwa tingkat insiden cedera yang tinggi pada nelayan muda dan selama bulan musim dingin. Memar dan patah tulang yang paling sering terjadi mengenai jari-jari dan tangan, sedangkan terjatuh dan kecelakaan yang berkaitan dengan mesin adalah penyebab paling umum. 
Berdasarkan survei yang telah dilakukan, diketahui bahwa telah terjadi kecelakaan kerja pada nelayan saat melakukan pekerjaannya selama melaut dan adanya keluhan yang dialami saat bekerja seperti nyeri punggung dan gatal-gatal. Berdasarkan hal diatas maka penulis ingin mengetahui bagaimana gambaran keselamatan dan kesehatan kerja pada nelayan di Pos Upaya Kesehatan Kerja (Pos UKK) Puskesmas Belawan.

Penelitian ini secara umum bertujuan untuk mendapatkan gambaran keselamatan dan kesehatan kerja pada nelayan di Pos Upaya Kesehatan Kerja (Pos UKK) Puskesmas Belawan. Tujuan penelitian secara khusus adalah untuk mengetahui kecelakaan kerja dan keluhan yang dirasakan pada saat bekerja yang pernah terjadi pada nelayan di Pos Upaya Kesehatan Kerja (Pos UKK) Puskesmas Belawan.

\section{Metode}

Penelitian ini merupakan penelitian deskriptif, data primer dikumpulkan dengan menggunakan kuesioner dan wawancara kepada responden. Lokasi penelitian dilakukan di Pos UKK wilayah kerja Puskesmas Belawan. Sampel pada penelitian ini sebanyak 16 responden yang diambil secara purposive, yaitu nelayan anggota Pos UKK yang tidak melaut pada saat penelitian berlangsung.

\section{Hasil Penelitian}

\subsection{Gambaran Kecelakaan Kerja Yang Pernah Terjadi Pada Responden}

Table. 1. Distribusi Kejadian Kecelakaan Kerja Pada Respondedn Tahun 2016

\begin{tabular}{llll}
\hline No & Kecelakaan Kerja & Frekuensi (a) & Persentase (\%) \\
\hline $\mathbf{1}$ & Ya & 14 & 87.5 \\
2 & Tidak & 2 & 12.5 \\
& Jumlah & 16 & 100 \\
\hline
\end{tabular}

Tabel 1 menggambarkan bahwa sebanyak 14 respondedn (87.5\%) mengalami kecelakaan kerja, dan 2 respondedn $(12,5 \%)$ tidak mengalami kecelakaan kerja.

Table. 2 Jenis Kecelakaan Kerja Yang Dialami RespondenTahun 2016

\begin{tabular}{llll}
\hline No & Jenis Kecelakaan & Frekuensi (a) & Persentase (\%) \\
\hline $\mathbf{1}$ & Terpleset & 2 & 14.29 \\
2 & Karam Kapal & 1 & 7.14 \\
3 & Tenggelam & 2 & 14.29 \\
4 & Kena bisa Binatang Laut & 5 & 35.71 \\
$\mathbf{5}$ & Dipatuk Ular & 1 & 7.14 \\
6 & Kena Engkol Mesin & 1 & 7.14 \\
7 & Kena Jaring & 1 & 7.14 \\
8 & Kena Pisau & 1 & 7.14 \\
\hline Jumlah & & 14 & 100 \\
\hline
\end{tabular}

Tabel 2 menggambarkan jenis kecelakaan kerja yang terbanyak terjadi adalah terkena bisa binatang laut sebanyak 5 responden $(35,71 \%)$, tenggelam dan terpeleset sebanyak 2 responden $(14,29 \%)$, 
Table. 3 Distribusi Kejadian Kecelakaan Kerja Berdasar Usia Responden Tahun 2016

\begin{tabular}{llllll}
\hline \multirow{2}{*}{ No } & \multirow{2}{*}{ Usia (Tahun) } & \multicolumn{2}{l}{ Kecelakaan } & \\
& & Ya & $(\%)$ & Tidak & $(\%)$ \\
\hline 1 & $\leq 46$ Tahun & 9 & 56.25 & 1 & 6.25 \\
2 & $\geq 46$ Tahun & 5 & 31.25 & 1 & 6.25 \\
\hline Jumlah & & 14 & 87.50 & 2 & 12.50 \\
\hline
\end{tabular}

Tabel 3 diatas dapat dilihat bahwa yang paling banyak mengalami kecelakaan kerja pada usia $\leqslant 46$ tahun yaitu sebanyak 9 responden $(56,25 \%)$.

Table. 4. Distribusi Kejadian Kecelakaan Kerja Berdasarkan Masa Kerja Responden Tahun 2016

\begin{tabular}{llllll}
\hline \multirow{2}{*}{ No } & \multirow{2}{*}{ Masa Kerja (Tahun) } & \multicolumn{2}{l}{ Kecelakaan } & Tidak & $(\%)$ \\
\hline 1 & Ya & $(\%)$ & 1 & 6.25 \\
2 & $\leq 20$ Tahun & 10 & 62.50 & 1 & 6.25 \\
\hline Jumlah & $\geq 20$ Tahun & 4 & 25 & 1 & 12.50 \\
\hline
\end{tabular}

Tabel 4 diatas menggambarkan bahwa responden dengan masa kerja $\leqslant 20$ tahun paling banyak mengalami kecelakan kerja yaitu sebanyak 10 orang $(62,50 \%)$.

\subsection{Gambaran Keluhan Yang Dirasakan Responden Saat Bekerja}

Table. 5. Distribusi Keluhan Yang Dirasakan Responden Saat Bekerja Tahun 2016

\begin{tabular}{llll}
\hline No & Keluhan yang dirasakan & Frekuensi & Persentase (\%) \\
\hline 1 & Ya & 11 & 68.75 \\
2 & Tidak & 5 & 31.25 \\
\hline Total & & $\mathbf{1 5}$ & $\mathbf{1 0 0}$ \\
\hline
\end{tabular}

Tabel 5 menggambarkan bahwa sebanyak 11 responden (68,75\%) mengalami keluhan pada saat bekerja, dan 5 responden $(31,25 \%)$ tidak mengalami kecelakaan kerja

Table. 6. Jenis Keluhan Yang Dirasakan Responden Saat Bekerja Tahun 2016

\begin{tabular}{llllll}
\hline No & Keluhan yang Dirasakan & Ya & $(\%)$ & Tidak & $(\%)$ \\
\hline 1 & Nyeri Punggung & 8 & 50 & 8 & 50 \\
2 & Gatal Gatal & 3 & 18.75 & 13 & 81.25 \\
3 & Pusing & 3 & 18.75 & 13 & 81.25 \\
4 & Gangguan Pendengaran & 1 & 6.25 & 15 & 93.75 \\
5 & Tangan terasa kebas & 2 & 12.50 & 14 & 87.50 \\
6 & Muntah & 2 & 12.50 & 14 & 87.50 \\
7 & Batuk & 3 & 18.75 & 13 & 81.25 \\
8 & Sakit Pinggang & 1 & 6.25 & 15 & 93.75 \\
\hline
\end{tabular}


Berdasarkan tabel 6 diatas diketahui bahwa keluhan yang paling banyak dirasakan oleh responden adalah nyeri punggung yaitu sebesar 50\%, pada saat ditanyakan ada beberapa responden mengalami lebih dari satu keluhan.

Table. 7. Distribusi Keluhan Yang Dirasakan Responden Saat Bekerja Berdasar Usia Tahun 2016

\begin{tabular}{llllll}
\hline \multirow{2}{*}{ No } & \multirow{2}{*}{ Usia (Tahun) } & \multicolumn{2}{l}{ Keluhan } & & \\
& & Ya & $(\%)$ & Tidak & $(\%)$ \\
\hline 1 & $\leq 46$ Tahun & 5 & 31.25 & 2 & 12.5 \\
2 & $\geq 46$ Tahun & 6 & 37.50 & 3 & 18.75 \\
\hline Jumlah & & 11 & 68.75 & 5 & 31.25 \\
\hline
\end{tabular}

Tabel 7 menggambarkan bahwa responden yang paling banyak mengalami keluhan saat bekerja adalah usia $>46$ tahun yaitu sebesar $37,50 \%$.

Table. 8. Distribusi Keluhan Yang Dirasakan Responden Saat Bekerja Berdasarkan Masa Kerja Tahun 2016

\begin{tabular}{llllll}
\hline \multirow{2}{*}{ No } & \multirow{2}{*}{ Masa Kerja (Tahun) } & \multicolumn{2}{l}{ Keluhan } & & \\
& & Ya & $(\%)$ & Tidak & $(\%)$ \\
\hline 1 & $\leq 20$ Tahun & 8 & 50 & 2 & 12.5 \\
2 & $\geq 29$ Tahun & 3 & 18.75 & 3 & 18.75 \\
\hline Jumlah & & 11 & 68.75 & 5 & 31.25 \\
\hline
\end{tabular}

Tabel 8 menggambarkan bahwa responden yang paling banyak mengalami keluhan saat bekerja sebesar $50 \%$ dengan masa kerja $\leqslant 20$ tahun.

\section{Pembahasan}

Kecelakaan kerja merupakan kejadian yang tidak terduga dan tidak diharapkan. Kejadian kecelakaan yang paling banyak terjadi pada responden adalah pada usia muda ( $\leq 46$ tahun ), yaitu sebesar 56,25\% dengan masa kerja $\geq 20$ tahun yaitu sebesar 62,50\% menurut asumsi penulis dikarenakan usia ini belum banyak pengalaman kerja.

Penelitian ini sejalan dengan Triwibowo dan Pusphandari [10] serta Sucipto [8] banyak alasan pekerja dengan golongan umur muda kecenderungan mengalami kecelakaan kerja lebih tinggi bila dibandingkan dengan para pekerja yang mempunyai umur tua, antara lain pada pekerja umur muda cenderung kurang perhatian, kurang disiplin, ceroboh dan tergesa-gesa, hasil penelitian di Amerika mengungkapkan bahwa pekerja usia muda biasanya kurang pengalaman dalam bekerja. Tingginya pengalaman dan keterampilan akan disertai penurunan angka kecelakaan kerja, kewaspadaan terhadap kecelakaan kerja akan bertambah sejalan dengan bertambah masa kerja.

Bekerja aman dan hati-hati sangat diperlukan dalam aktivitas sehari-hari dalam bekerja agar terhindar dari kecelakaan kerja, sehingga perilaku yang mencerminkan keselamatan dan keselahatan kerja dapat menjadi budaya ditempat kerja. Menurut Somad [7] budaya Keselamatan dan Kesehatan Kerja (K3) yang baik baru terbentuk setelah dilakukan usaha penerapan program K3 dan pencegahan kecelakaan secara konsisten dan bersifat jangka panjang.

Kecelakaan kerja yang paling banyak terjadi pada responden adalah terkena bisa binatang laut, yaitu sebesar $35,71 \%$, selain itu jenis kecelakaan yang terjadi pada responden adalah terpeleset, tenggelam, kapal karam, kena jaring, pisau dan engkol mesin. Menurut Suma'mur [9] ada beberapa ikan dan binatang laut yang berduri sehingga melukai nelayan atau mengandung racun berbahaya. Terkait dengan kecelakaan kerja yang terjadi ada beberapa upaya pencegahan kecelakaan yang dapat dilakukan antara lain nelayan harus pandai berenang, kesehatan fisik harus baik, tersedia alat pertolongan pertama pada kecelakaan, perahu lapuk dan tali temali yang usang tidak lagi dipergunakan. 
Selain kecelakaan kerja, responden juga mengalami beberapa keluhan pada saat bekerja, keluhan yang paling sering dirasakan adalah nyeri-nyeri bagian punggung yaitu sebesar 50\%, hal ini diasumsikan karena cara dan posisi kerja dari nelayan yang tidak ergonomis, misalnya saat menggangkat beban dan menarik jaring. Menurut Rijanto [6] mengangkat adalah pekerjaan biasa yang berhubungan dengan punggung bawah, banyak cedera yang terjadi tidak disebabkan oleh kejadian seketika, tetapi terbentuk melalui kurun waktu. Hasil penelitian yang dilakukan oleh Budiman [2], terdapat hubungan yang signifikan antara kejadian mosculoskeletal disorder (MSDs) dengan posisi kerja pada nelayan tangkap. Upaya pencegahan terkait nyeri punggung ini menurut Anies [1] dapat dilakukan dengan sikap tubuh yang baik, seperti tubuh tegak dan jangan menyangga beban berat pada satu bahu.

\section{Kesimpulan dan Saran}

Responden yang pernah mengalami kecelakaan kerja adalah sebesar 87,5\%, jenis kecelakaan kerja yang paling banyak terjadi adalah terkena bisa binatang laut yaitu sebesar 35,71\% dengan usia $\leq 46$ tahun yaitu sebesar 56,25\% dan masa kerja $\geq 20$ tahun yaitu sebesar $62,50 \%$. Responden yang merasakan keluhan saat bekerja adalah sebanyak $68,75 \%$, jenis keluhan yang dirasakan pada saat bekerja yang paling banyak dirasakan oleh responden adalah nyeri punggung yaitu sebesar 50\%, dengan 37,50 \% responden yang berusia > 46 tahun dan 50\% responden masa kerjanya $\leq 20$ tahun.

Disarankan agar nelayan lebih berhati-hati pada saat bekerja, memperbaiki sikap kerja agar lebih ergonomi dan menggunakan pakaian pelindung dengan lengan panjang, memperhatikan kondisi perahu dan alat kerja serta memakai pelampung.

\section{Referensi}

[1] Anies. (2005) Penyakit Akibat Kerja. Berbagai Penyakit Akibat Lingkungan Kerja dan Upaya Penanggulangannya, Penerbit PT. Elex Media Komputindo, Kelompok Gramedia, Jakarta.

[2] Budiman, Farid. (2015) Hubungan Posisi Kerja Angkat dengan Keluhan Musculoskeletal Disorders pada Nelayan Tangkap di Muara Angke Pluit Jakarta Utara : Universitas Indonusa Esa Unggul. Vol.12 No.1

[3] Depkes RI.(2005). Pedoman Pelaksanaan Upaya Kesehatan Kerja di Puskesmas, Jakarta

[4] Dharmawirawan, DA dan Robiana Modjo. (2012) Identifikasi Bahaya Keselamatan dan Kesehatan Kerja pada Penangkapan Ikan Nelayan Muroami. FKM UI : Jurnal Kesehatan Masyarakat Nasional. Vol.6.No.4

[5] N. Bull et.al. (2001) Occupational Injuries to Fisheries Workers in Norway Repoerted to Insurance Companies from 1991 to 1996. University of Bergen : Journal Occupational Medicine : Vol.51 No.5

[6] Rijanto, BB. (2011) Pedoman Pencegahan Kecelakaan Di Industri, Penerbit Mitra Wacana Media, Jakarta.

[7] Somad, Ismed. (2013) Teknik Efektif Dalam Membudayakan Keselamatan dan Kesehatan Kerja, Penerbit Dian Rakyat, Jakarta.

[8] Sucipto, CD. (2014) Keselamatan dan Kesehatan Kerja, Gosyen Publishing, Cetakan I, Yogyakarta.

[9] Suma'mur. (2014) Higiene Perusahaan dan Kesehatan Kerja (Hiperkes), CV.Sagung Seto, Cetakan I, Jakarta.

[10] Triwibowo, C dan Pusphandani M.E. (2013) Kesehatan Lingkungan dan K3, Penerbit Nuha Medika, Yogyakarta. 